\title{
A Suspended Floor for High-Performance Electron Microscopy and Nanoscience
}

\author{
Charles Eric Brown, ${ }^{*}$ Alan W. Nicholls, ${ }^{*}$ Thomas J. \\ Royston, ${ }^{* *}$ Waleed M. D'Keidek ${ }^{* * *}$ \\ ${ }^{*}$ Research Resources Center, ${ }^{* *}$ Department of Mechanical \\ and Industrial Engineering, ${ }^{* * *}$ Office of Capital Programs, \\ University of Illinois at Chicago \\ charlieb@uic.edu
}

\section{Introduction}

The recent article in this journal by O'Keefe et al. [1] provides an excellent introduction to the complexities that must be considered when embarking on the installation of a high-resolution electron microscope. It should not pass one's notice, however, that the advent of nanoscience has placed ever stricter attention on the control of vibration not just for analytical instrumentation but also for fabrication facilities. In addition to the thick isolated concrete slab-ongrade described in the above article, designs are coming into use (Fig. 1) that incorporate rigid "waffle" floor structures on closely spaced building columns $[2,3]$ and pneumatically isolated inertia slabs as are used, for example, in the subterranean portion of the NIST Advanced Metrology Laboratory [4]. Each of these approaches might with time also find applications in the design of electron microscopy laboratories. However, each has the problem of rather high expense of construction. In this article we describe an unlikely, but inexpensive, installation in 1998 of a JEOL JEM-2010F TEM/STEM (scanning transmission electron microscope) on a suspended concrete slab floor in the former cafete-

Rigid Waffle on Close-Spaced Columns

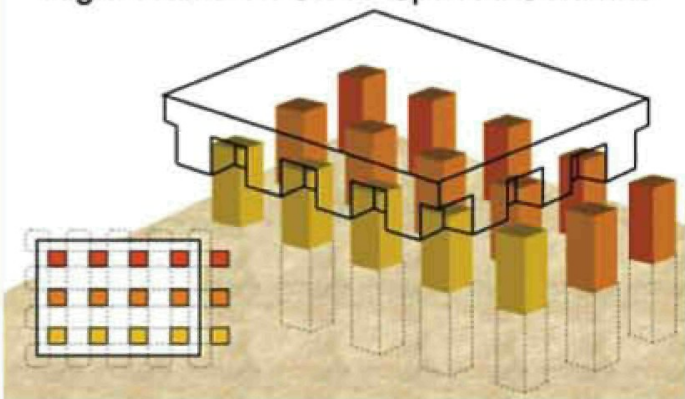

\section{Pneumatically Isolated Inertia Slab}
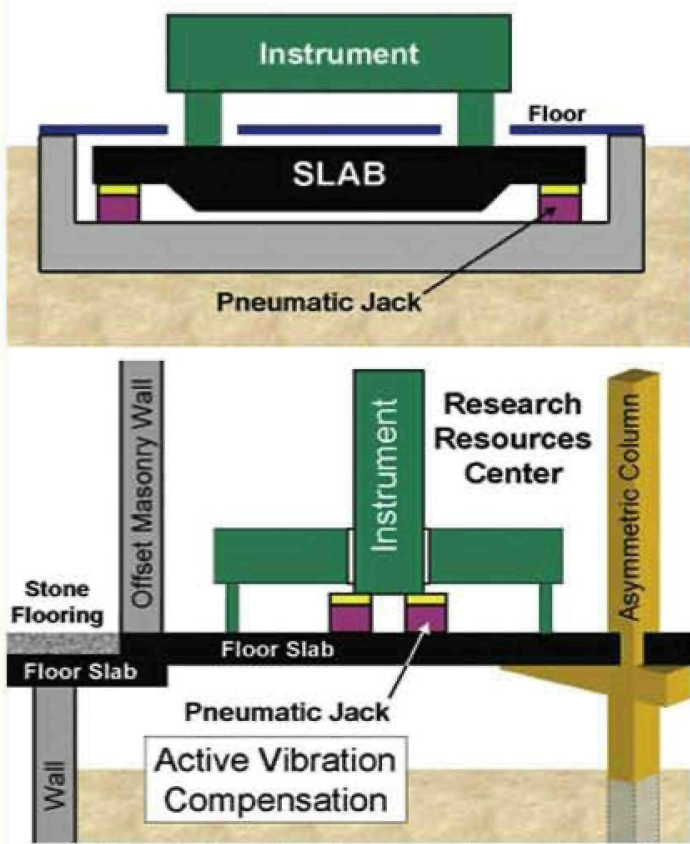

Figure 1. Comparison in conceptual terms of methods for vibration control in nanoscience buildings and in the installation of the JEOL JEM-2010F TEM/STEM. ria of an unusual fifty-year-old building designed by Walter Netsch. An initial site survey indicated that this suspended floor would perform better than slab-on-grade microscope facilities on our campus. and subsequent studies have demonstrated that it meets NIST-A classification (if active isolation is used for very low frequencymotion and comes close to meeting classification NISTA1. The intent of this article is to present what is known about this floor and to suggest clues it might provide for the design and construction of suspended floors that might provide less expensive options for both electron microscopy and nanoscience research and fabrication facilities in active urban areas.

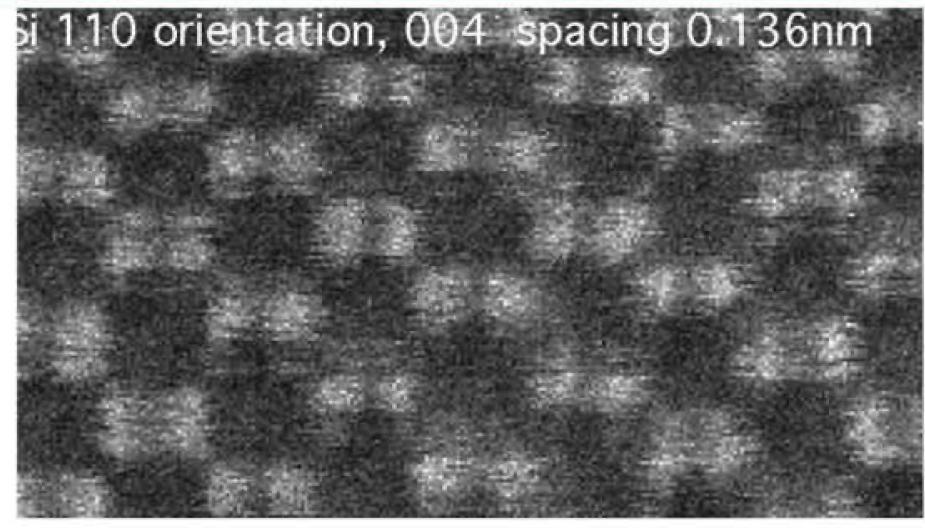

Figure 2. Z-Contrast STEM micrograph of Silicon in the $\langle 110\rangle$ orientation. The $\{004\}$ spacing is $0.136 \mathrm{~nm}$. The theoretical limit of the diameter of the microscope's electron beam is $0.13 \mathrm{~nm}$ at focus.

\section{Performance of JEOL JEM-2010F TEM/STEM on Suspended Concrete Slab Floor}

The Research Resources Center (RRC) of the University of Illinois at Chicago installed the first JEOL JEM-2010F TEM/STEM in North America to characterize materials at the atomic level by High Angle Dark Field (HADF) imaging in the scanning transmission mode. The instrument was installed on an IDE (Integrated Dynamics Engineering) pneumatic active vibration cancellation system on an 8-inch thick suspended concrete slab floor.

The instrument exceeded the contractual specifications for resolution, and ultimate resolution was demonstrated by imaging the $\{004\}$ spacing $(0.136 \mathrm{~nm})$ in a Silicon $\langle 110\rangle$ oriented single crystal [5]. The image in Fig. 2 shows obvious separation of these closely spaced columns of atoms. To the best of our knowledge, no one else had published this level of performance with a commercial $200 \mathrm{KV}$ electron microscope of any kind at that time. Since the diameter of the probe is expected not to be less than $0.12 \mathrm{~nm}$ and the distance between the atoms is only $0.136 \mathrm{~nm}$, this instrument is working near its theoretical limit. Interferences from external sources appear not to affect the instrument.

\section{Design of Microscope Suite}

To obtain the spatial resolution demonstrated in Fig. 2, it is necessary to direct a small diameter $(0.13 \mathrm{~nm})$ beam of electrons from the field emission source, through the sample and onto the detector over the distance of a few feet. Beam deflection, motion, and distortion of the microscope column at the specimen needs to be limited to not more than about $0.1 \mathrm{~nm}$.

beam deflection by variations in stray magnetic fields was minimized by installing our two vertical-bore NMR and horizontal 8 Tesla wide bore EPR superconducting magnets at the opposite end of the laboratory (Fig. 3).Motion and distortion of the microscope column can arise from more than just floor vibration. Variations in atmospheric pressure primarily affect the position of the sample holder, which leads to drift. This can be overcome easily by putting a chamber with an O-ring seal over the exposed end of the sample holder and the specimen drives. Expansion and contraction of the microscope column can be minimized by very closely controlling the temperature of both the room air and the cooling water. Intake air is first conditioned by the building air handling units in the basement beneath the RRC, and then the air is reconditioned to tighter specifications by auxiliary air handling units mounted on the roof and by hot-water reheat coils in the ductwork outside the STEM room. The tight tolerance for room temperature control needs to be accomplished with a minimum of air flow to avoid both ductwork noise and turbulence as the air passes the microscope. This was achieved by providing air supply and return by way of oversized ducts that open into spaces behind opposing "fake" walls, which have 1 - $\mathrm{ft}$ high openings at floor level almost the entire width of the room (Fig. 4). The temperature of the chilled water for cooling the lenses also needs to be closely controlled to avoid expansion and contraction. A flat plate exchanger is used rather than a dedicated water chiller since this permits close temperature control near the microscope with a small centrifugal water pump in the exchanger as the only source of vibration. Cold water is provided for both the roof-mounted auxiliary air handling units and the laboratory process water by a chiller installed outside the building. The entire microscope room has sound proofing on and in the walls and ceiling, and the support equipment is housed in a separate small room behind the sound proofing. 


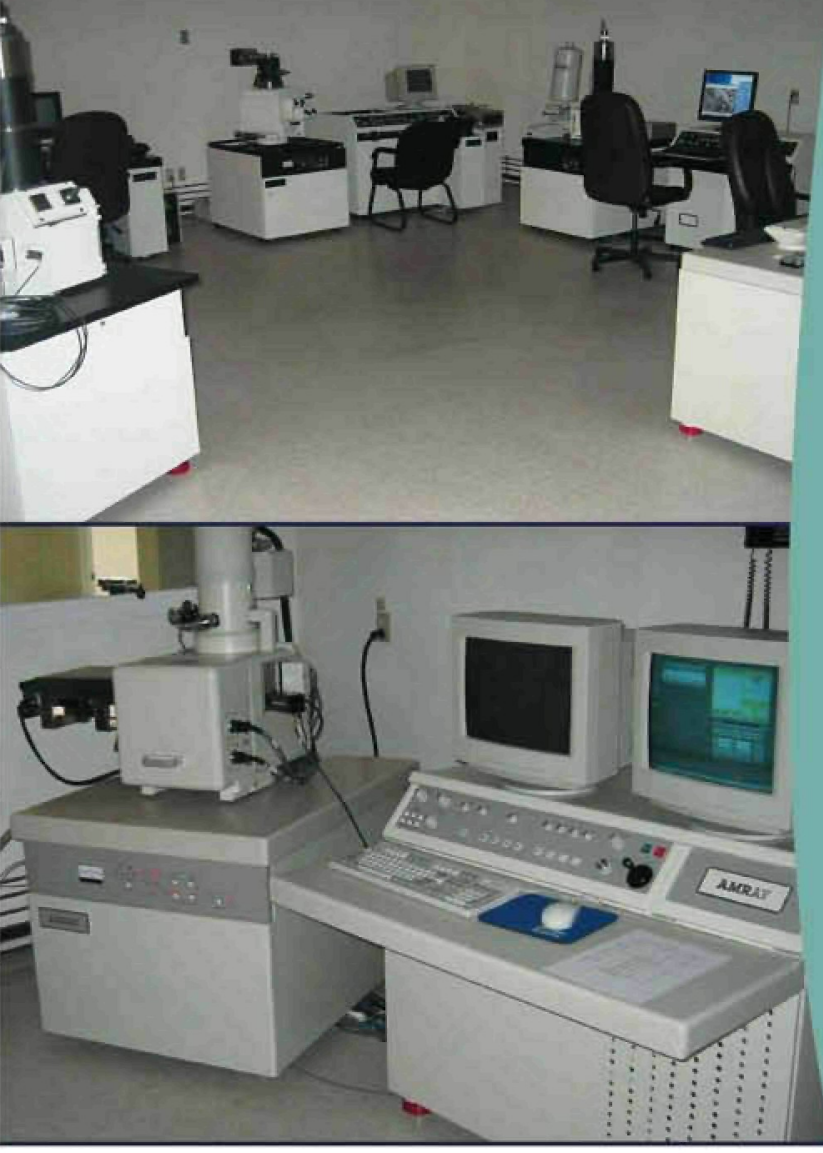

\section{Pre-Owned SEMs -}

\section{The Smart \& Easy Alternative to Buying New}

Why buy a new Scanning Electron Microscope when SEMTech Solutions offers a smarter and easier solution?

We specialize in pre-owned, rebuilt and upgraded products, including:

- Field Emission SEMs

- Digital Imaging

- Computer and EDS Upgrades

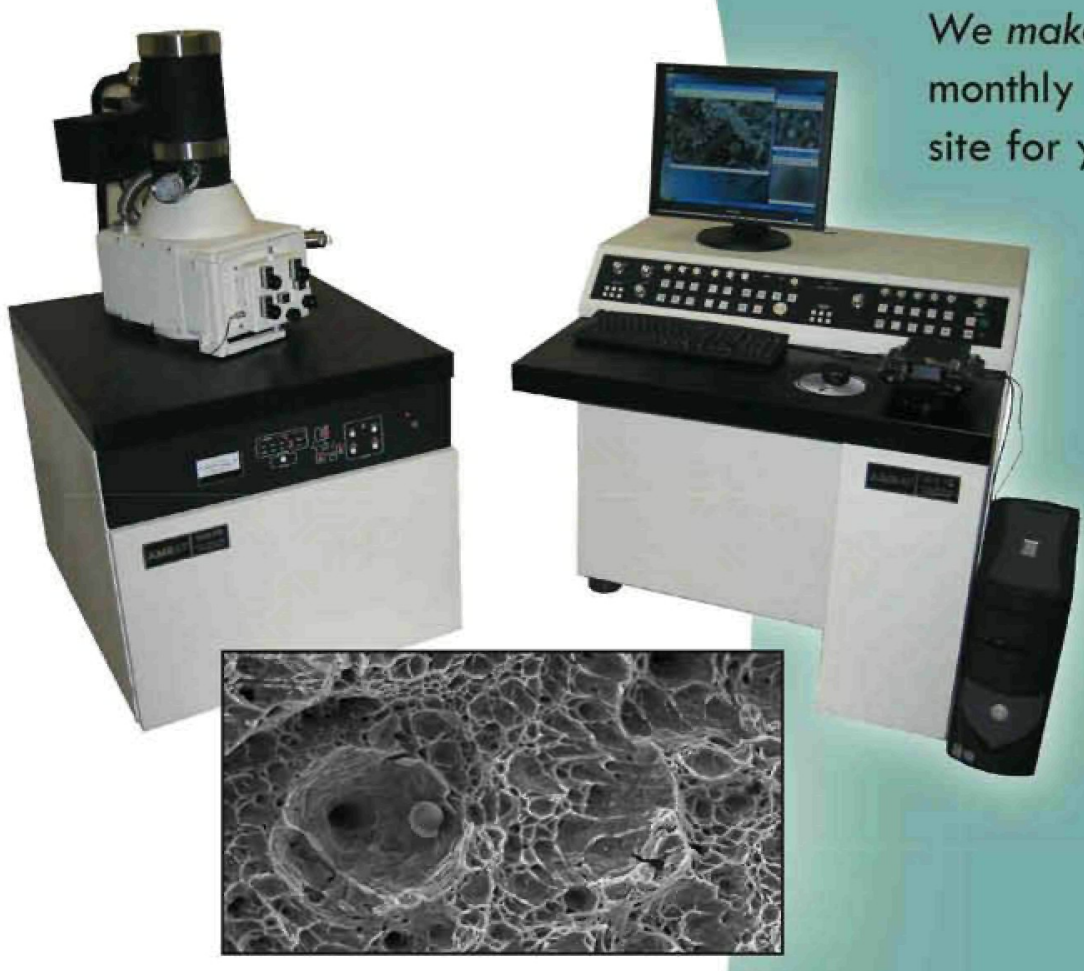

We make it smart by offering affordable prices, monthly lease options and an up-to-date web site for your convenience.

We make it easy by offering hands-on, in-person equipment demonstrations at our Massachusetts facility. Scheduling a demo is simple; just call us at 978.663 .9822 for an appointment.

Visit us at www.semtechsolutions.com to get more information on all SEMTech Solutions products and services.

Smart. Easy.

- SEMTech Solutions, Inc.

- SEMTech Solutions, Inc.

6 Executive Park Drive

North Billerica, MA 01862

$978 \cdot 663 \cdot 9822$

www.semtechsolutions.com 


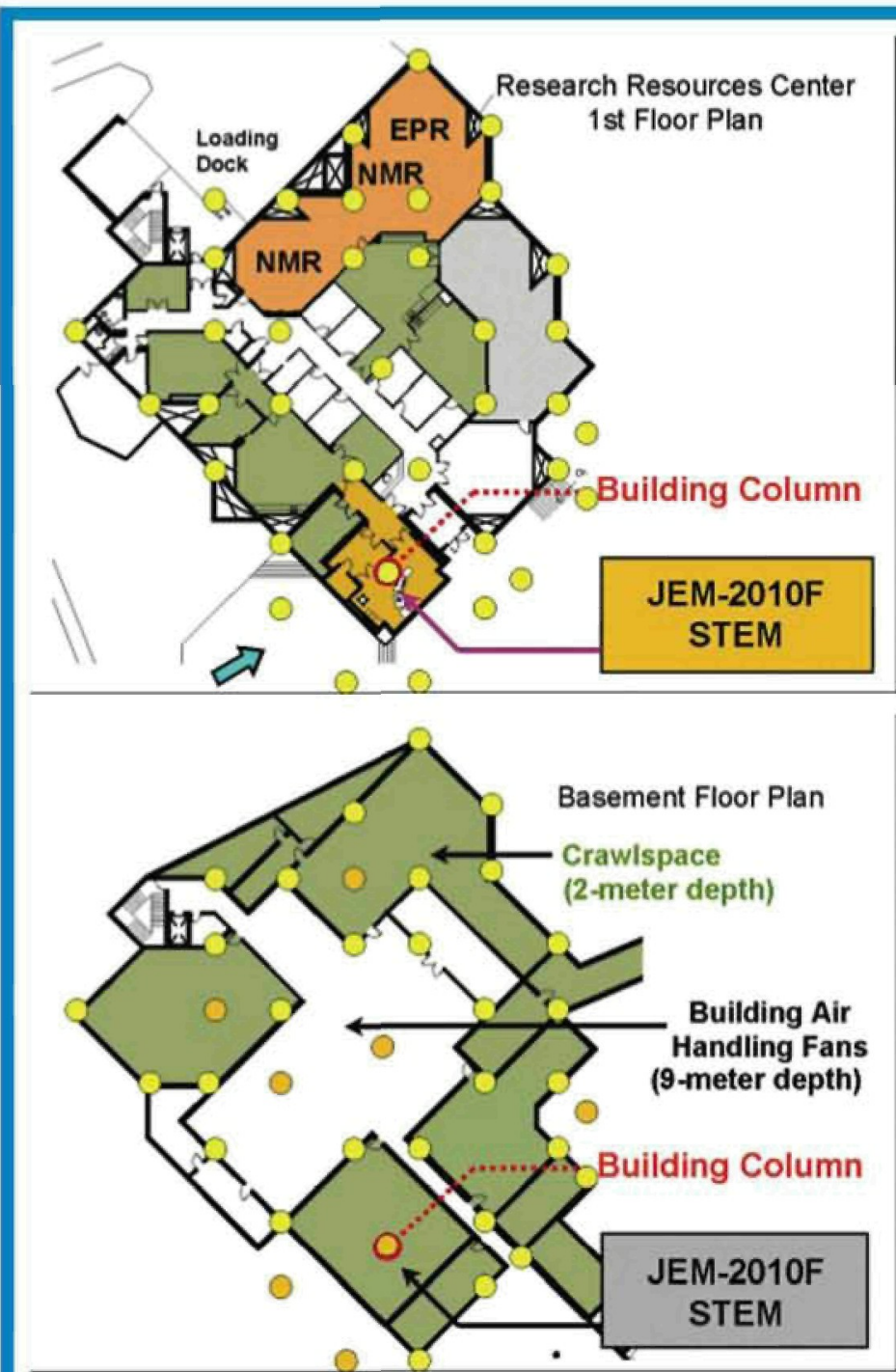

Figure 3. Floor plans of the Research Resources Center on the first floor of the building (Top) and of the basement beneath (Bottom). The positions of building columns on the first floor are indicated by the yellow circles in the top drawing. These positions also are highlighted in the drawing of the basement. Most of the building columns rest on load bearing foundations and basement walls. Only the columns indicated in orange are free-standing. The labeled building column corresponds with the column at the center of the radial array of ceiling support beams in Fig. 4. Photographs of this column are presented in Fig. 5.

\section{Generic Vibration Standards to Assess Ambient Conditions \\ in Nanoscale Facilities}

The best vibration standard for high-precision instrumentation (in this case, an electron microscope) will be specific to that particular instrument as well as to the intended installation site. The microscope may have dynamic behavior that interacts (i.e. is coupled) with the structural dynamic behavior of the installation site, because it is a substructure of the total system. A manufacturer can provide site selection specifications that place a limit on the input to this substructure. However, unless this specification is carefully defined, there might be unanticipated interactions that affect the imposed limit. To design a facility to accommodate a wide range of high-precision instrumentation of varying dynamic behavior, a set of generic criteria are needed.

Prior approaches for specification of microscope installation sites and nanoscale facilities utilized primarily frequency-based [2,4,6-9], or time-based [3] criteria, or emphasized displacement $v$ s. velocity $v s$. acceleration limits. As a result, it is more common to find a variety of measurements in the literature, including power spectral density, $1 / 3$ octave spectrally filtered measurements and r.m.s. levels of motion that cannot be easily compared and may, in some cases, be irrelevant. The most widely sanctioned vibration standards, ISO 2000, which attempt to identify ideal generic criteria for nanoscale facilities

(ISO/TS 10811-1 and 10811-2, "Mechanical vibration and shock - Vibration and shock in buildings with sensitive equipment") were adopted in $2000[10,11]$. The first standard discusses measurement and evaluation techniques, and the second covers classification based on the types of measurements described in the first standard. The measurement approach involves taking time history measurements of acceleration or velocity at a number of key points, being sure to capture responses at times when potential disturbances are applied (e.g. passing vehicles on nearby roads, footfalls near equipment, etc.). These measurement records are then subjected to a filtering algorithm that produces what is called a "response-equivalent peak velocity spectrum". This provides a prediction of the maximum velocity that the sensitive instrumentation may undergo, depending on its resonant frequencies below $200 \mathrm{~Hz}$ and their associated $Q$ (inverse of critical damping) values. The criterion used to "rate" the facility after measurement is based on a spectral breakdown of velocity, acceleration and displacement in different frequency regimes. Additionally, the standard attempts to account for potential instrumentation dynamics and coupling to the facility through the filtering algorithm. This suggests that it

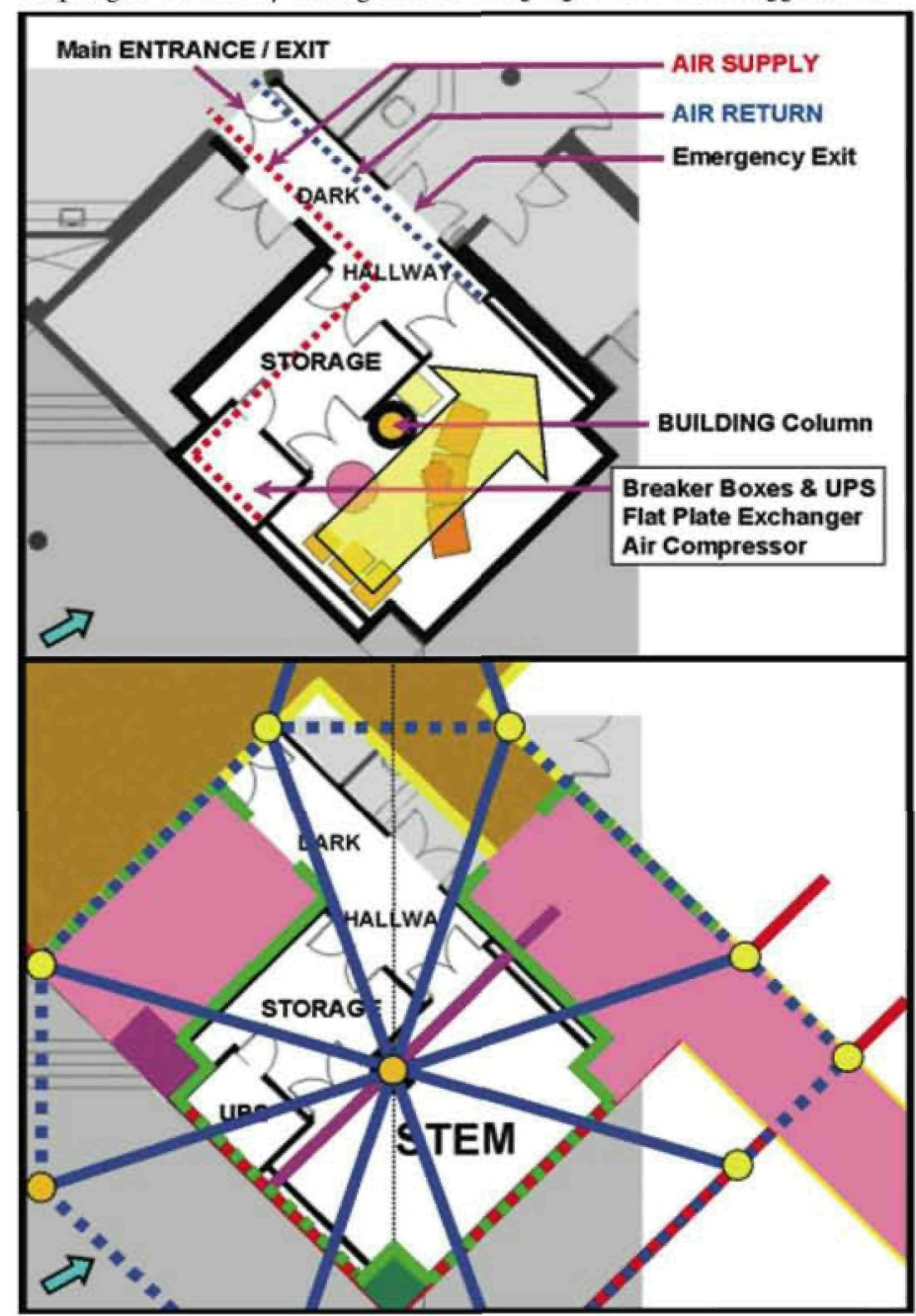

Figure 4. Floor Plans of STEM suite. (Top) General layout and direction of air flow. (Bottom) Building structure surrounding the STEM suite. Basement Level: Red, foundation. Yellow, basement wall. Brown, basement floor 9-meters below lab. First Floor: Light purple, 8-in thick slab depressed 5-in lower than the adjacent floor slab and covered with stone flooring (See Fig. 1 bottom). Gray-green, exterior 12-in thick slab with stone flooring depressed 11 -in below the laboratory floor. Dark purple, 24-in thick slab (under laboratory) and 19-in thick slab (under depressed slab with stone flooring). Green, heavy brick-faced masonry walls resting on first floor slab. Second floor: Blue, concrete beams that support second floor. Building columns on isolated caissons are shown in orange, and those resting on a basement wall or foundation are shown in yellow. A PowerPoint presentation that permits stepwise visualization of the individual building components is available on the Research Resources Center web site (www.rrc.uic.edu). 


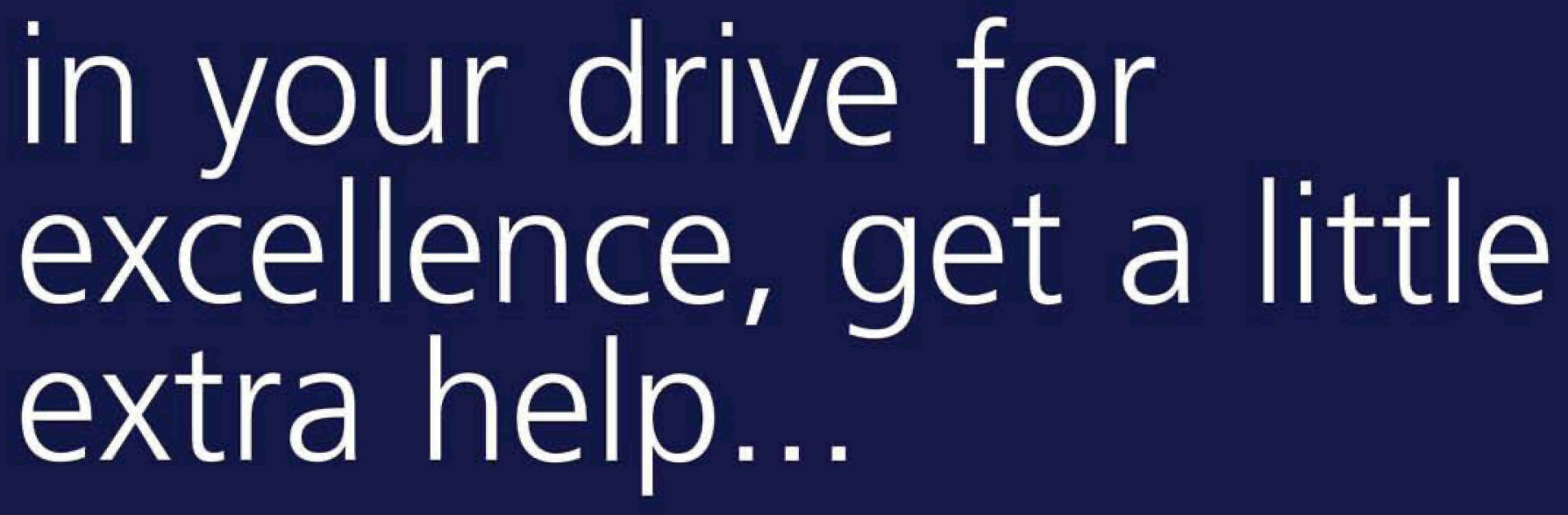

Today, it is no longer enough to make leading edge products.

Support, training, and top quality service are key elements of our unique solutions for microanalysis.

Before purchasing your next EDS, WDS or EBSD system, ask for your free guide to 'Microanalysis Explained', and see how Oxford Instruments can boost your drive to success.

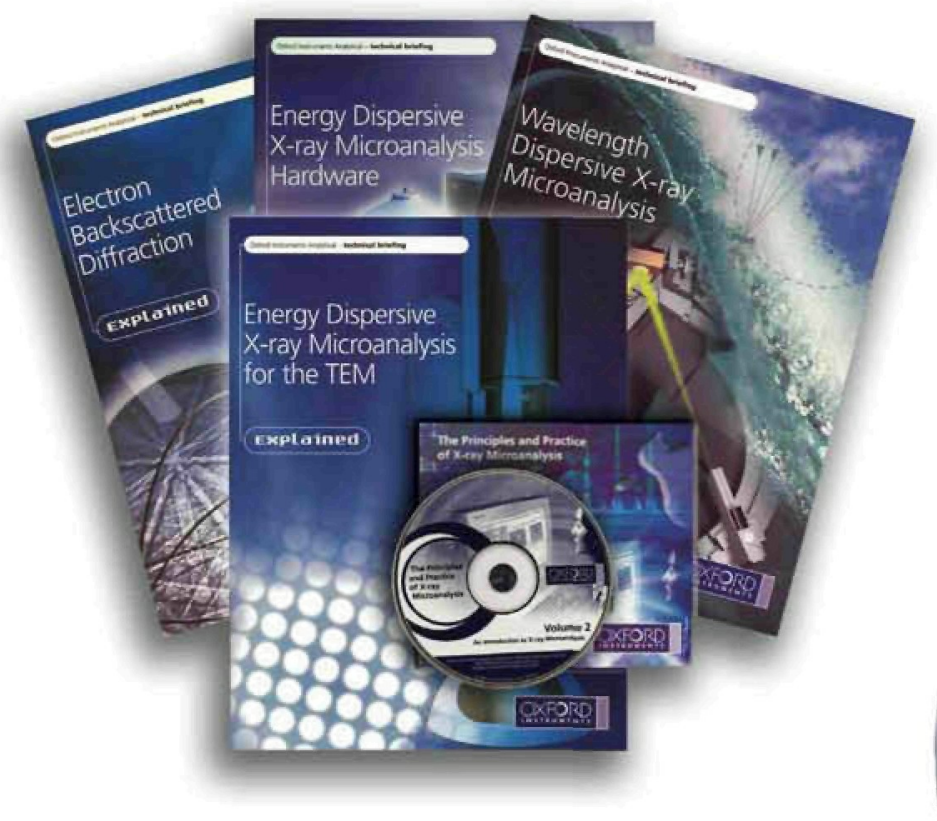

FREE 'MICROANALYSIS EXPLAINED' the complete guide available exclusively to you. Just email: info@ma.oxinst.com

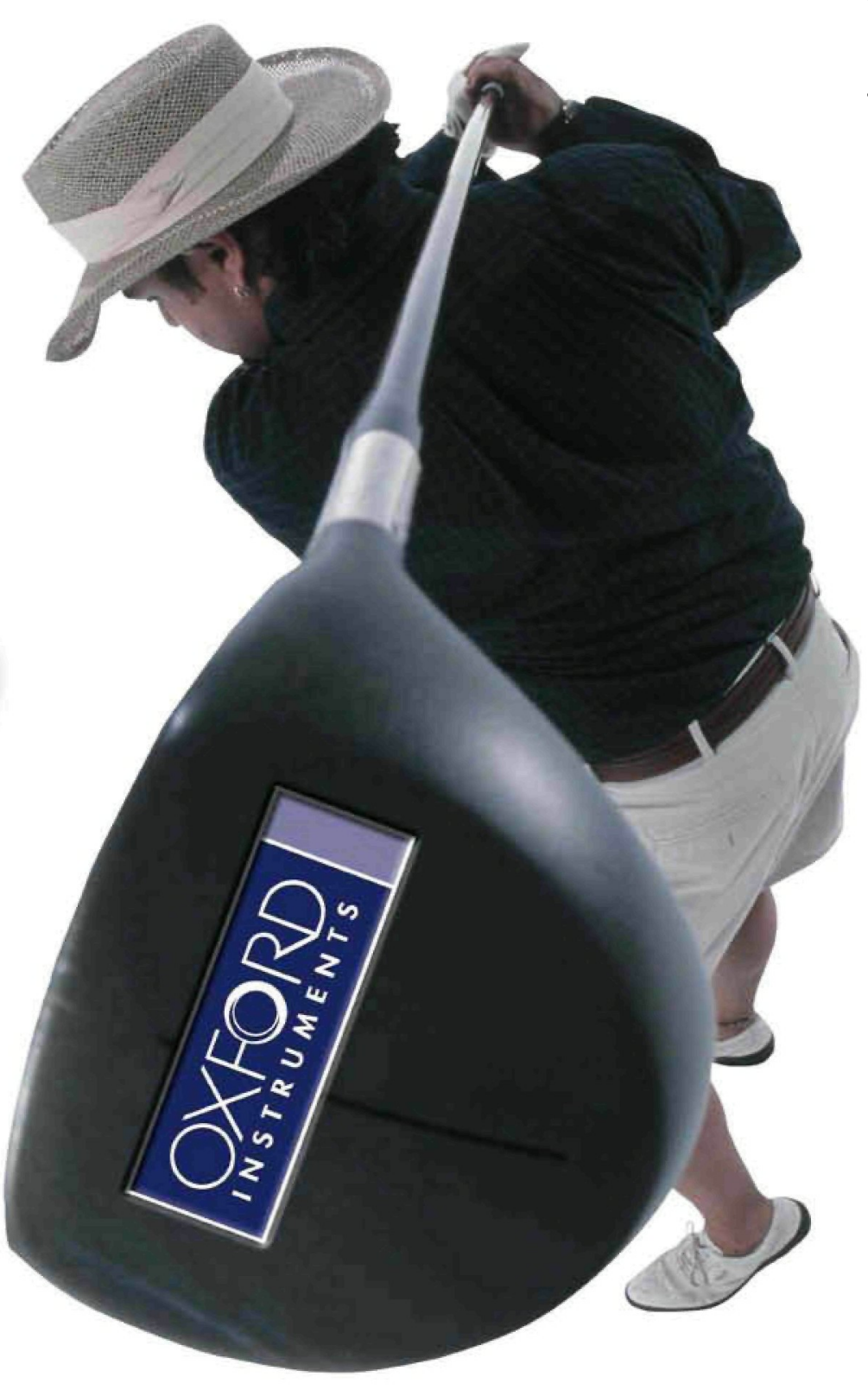

Oxford Instruments Analytical

Concord MA

Tel: +18004474717

Fax: +19783698287

Email: info@ma.oxinst.com

www.oxford-instruments.com 


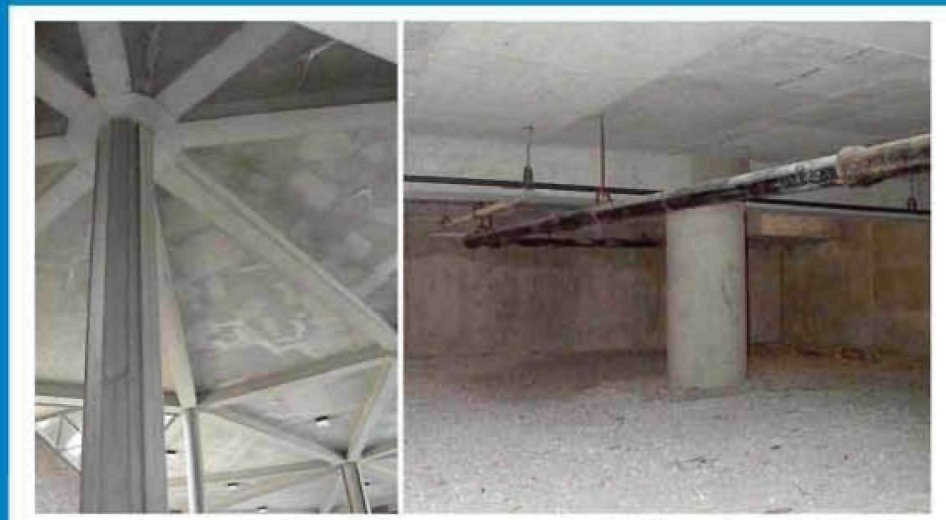

Figure 5. (Left) Radial beams supporting the floor above the STEM room and nearby labs. (Right) Space beneath the concrete floor slab that supports the JEOL JEM-2010F TEM/STEM. This picture shows the base of the building column, the asymmetric beam (running left-to-right across the top of the column) and the depressed 12-in thick floor slab of the exterior decorative wall indentation (appearing to the right of the column just behind the beam). The beam and 12-in thick depressed floor slab are indicated in Fig. 4 bottom as the dark purple line and gray-green square, respectively. The JEM-2010F is located roughly above the drain pipe where it passes behind the building column.

should be possible to install microscopes on a wider range of floor types than currently are recommended if the coupling of each microscope to the dynamics of its floor can be handled appropriately. The JEM-2010F installation described in this paper provides one such example.

\section{Performance of the Suspended Concrete Slab Floor beneath the JEOL JEM-2010F}

Pneumatic active vibration cancellation systems work extremely well when the motion of the floor is highly predictable, very low bandwidth and devoid of random spikes. Thus, we looked for an installation site with a floor that moves in a predictable manner at very low frequency with low amplitude AND filters out "spikes" in ground motion from outside sources. The site was chosen on the basis of accelerometer measurements performed by IDE. Much to our surprise, we learned when inspecting the architectural drawings of the building that the floor we had chosen was suspended.

Table 1. Comparison of Peaks in the Power Spectral Densities

(Microns / Second / $\mathrm{Hz}^{1 / 2}$ ) Measured by IDE

\begin{tabular}{|l|c|c|}
\hline & IEM-2010F Room & Slab on Grade \\
\hline Vertical & $4.4 @ 27.1 \mathrm{~Hz}$ & $11.8 @ 7.3 \mathrm{~Hz}$ \\
\hline Horizontal X & $5.5 @ 3.9 \mathrm{~Hz}$ & $9.5 @ 7.3 \mathrm{~Hz}$ \\
\hline Horizontal Y & $4.7 @ 3.9 \mathrm{~Hz}$ & $7.5 @ 7.3 \mathrm{~Hz}$ \\
\hline
\end{tabular}

Externally conducted study: Ambient Testing. Integrated Dynamics Engineering performed a site survey [12] at two different locations on the UIC campus as part of JEOL's site selection process (Table 1). The first location was the basement of the Medical Sciences Building (slab on grade). The second location was a cafeteria (now the RRC) in the Science \& Engineering South (SES) building (Fig. $3 \& 4$ ). Vibration measurements were made in 3 directions at the location where the equipment was to be placed using an IDE Triaxis Micro-Velocity vibration sensor type TAS- 1000 with preamplifier feeding into a 16 bit A/D converter embedded on a PCMCIA card (IOTECH Daq/216). IDE presented vibration velocity results in terms of time history plots $(\mu \mathrm{m} / \mathrm{sec})$ and power spectral density (PSD) $\left(\mu \mathrm{m}^{2} / \mathrm{sec}^{2} / \mathrm{Hz}\right)$ plots up to $400 \mathrm{~Hz}$, and tabulated peak values of the PSD plots in terms of $\mu \mathrm{m} / \mathrm{sec} / \sqrt{\mathrm{Hz}}$. Overall, it was found that the SES RRC suspended floor significantly outperformed slab-on-grade at the other nearby site.

Preliminary studies by the authors. Ambient Testing. Vibration measurements were made in 3 directions on the floor next to the installed JEM-2010F with three accelerometers (Vibrametrics Model 1030, Princeton Junction, NJ) arranged triaxially. Measurements were also taken on the column in the crawl space below the low-vibration room (Figs. 3 \& 5), on the floor of the 9-meter deep basement near the 2-meter deep crawl space (slab on grade) and on pavement exterior to the SES building near the low-vibration room (Exterior Pavement 1, Table 2) and 15 meters away on the street sidewalk (Exterior Pavement 2, Table 2). Measurements taken by IDE at 2 slab-on-grade locations in the basement of the Engineering Research Facility (ERF) building across the street from SES are included here for comparison. This building is of a more conventional rectangular, box-like geometry. It was expected that slab on grade measurements in its basement ought to be comparable to the basement in SES, as these buildings both have nominally the same distance to the main streets between and next to them (Taylor and Halsted Streets).

Accelerometer signals were conditioned with manufacturer-provided battery-powered amplifiers and input to an Agilent VXI E1433A 8 channel "digitizer + DSP" board controlled by Matlab via a IEEE 1394 firewire connection to a laptop PC. Based on an analysis of the specified noise limits of the various devices used, the projected threshold sensitivity of our system is about $10 \%$ of the lowest recorded values.

RMS values of vibration velocity and displacement were calculated by integrating the time records $(\sim 30 \mathrm{sec}$. sampled at $512 \mathrm{~Hz})$ of acceleration and calculating the root mean square. RMS values of vibration velocity measured in the low-vibration room in horizontal (north-south, east-west) and vertical directions based on 4 separate measurements ranged from 5 to 10 microns $/ \mathrm{sec}$. Corresponding RMS displacement values were nominally 0.1 microns. Similar measurements made in a room adjacent to the "low-vibration" room were in the 35 to 40 microns/sec range and 0.5 to 0.7 micron range, respectively. Measured RMS velocity values in the suspended "low-vibration" room were comparable to measured values in the crawl space and on the 9-meter deep basement floor (slab-on-grade). Measured RMS displacement values in the suspended "low-vibration" room were up to a factor of 2 lower than values in the crawl space and on the 9-meter deep basement floor.

O'Keefe et al. [1] stated that " $\ldots$...vibration velocity on the microscope foundation should be kept below 1 micrometer per second in the critical 1 to 5 $\mathrm{Hz}$ frequency range." A comparable measurement on the suspended concrete slab floor that is the subject of the present article showed that the velocity stayed below 1 micrometer per second at least up through $12 \mathrm{~Hz}$.

For further comparison with other studies conducted by IDE (e.g. Table 1) in the SES and ERF sites, power spectral densities (PSDs) of velocity and displacement were calculated. Tables 2 and 3 compare peak values in the PSD curves for various locations. In terms of displacement, the suspended "lowvibration" room outperforms the basement floor of SES (slab on grade) and crawl space, which in turn outperform slab on grade across the street in the ERF basement. In other words, while the overall RMS velocity levels for the "low-vibration" room, basement and crawl space are comparable, significant low frequency peaks in the spectral distribution of vibration are attenuated in the "low-vibration" room. The vibratory energy seems to be more dispersed spectrally, or at least strong lower frequency peaks in the disturbance have been filtered out, which upon integration yields a lower displacement level. This is in addition to the apparent overall better vibration stability of the SES building relative to a more conventional rectangular box-like building.

These measurements place the low-vibration site within the VC (Vibration Criteria) classification E based on PSD measurements. This is comparable to NIST-A classification (if active isolation is used for very low frequency motion) and is suitable for SEM, SPM, AFM, and other "submicron processes" and "atom pushing processes". According to many references, this performance should only be achievable with a slab on grade or concrete waffle on closely spaced columns [2]. In fact, the RRC site comes close to meeting classification NIST-A1, which was previously thought to be achievable only with a pneumatically isolated inertia slab (Fig. 1).

Driven response measurements. As an initial investigation of worst-case working conditions on this suspended floor, the response of the triaxial accelerometer to someone jumping 1 -meter away was recorded. Ideally, an estimate of the resonant frequencies and critical damping ratios of the room could be obtained from such a test. One would typically expect one fundamental frequency or a few low resonant frequencies below $50 \mathrm{~Hz}$ to dominate the response [13], with their values dependent on the suspended slab thickness and distances between load bearing walls and supporting columns. Typical time and frequency responses are shown in Fig. 6. Note that, while oscillatory behavior is clearly evident in the time domain plot, the spectral plot does not reveal any distinct, sharp resonant peaks below $50 \mathrm{~Hz}$. There are no clear dominant standing wave patterns, and energy is dispersed among a wider range of frequencies. This is in agreement with ambient PSD comparisons described above. 

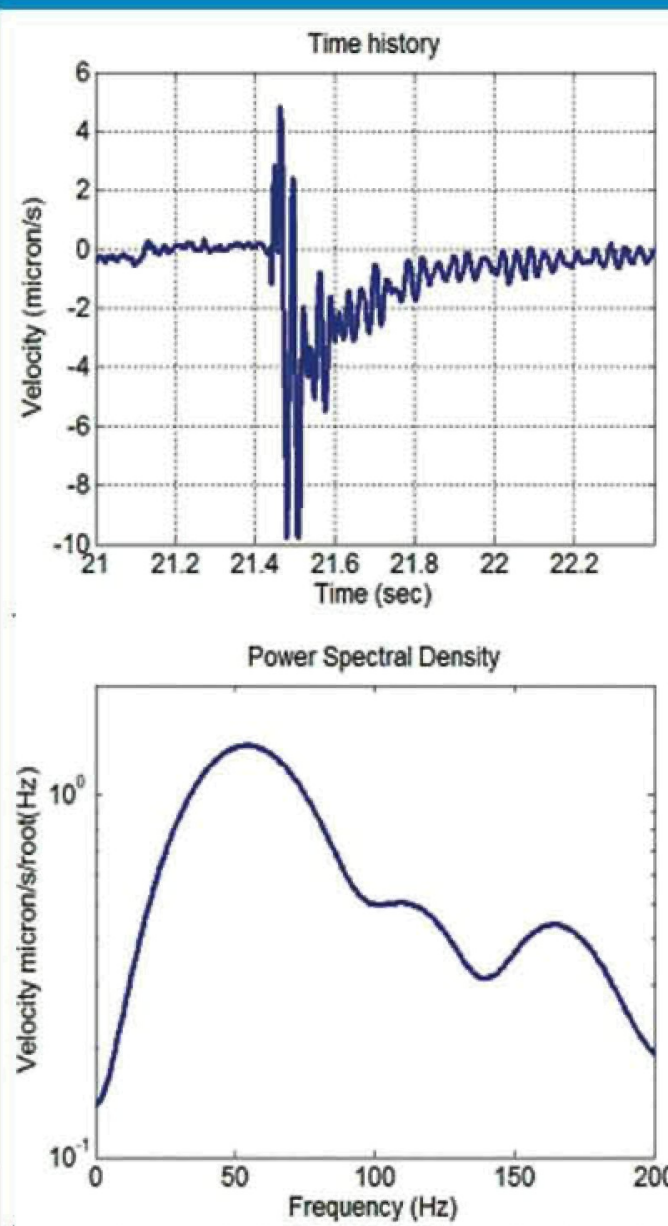

Figure 6. Vertical floor velocity (top) and power spectral density (bottom) in response to a "jump" 1 meter from sensor. by the suspended floor might be due to the significant asymmetry in the construction of this building.

Unlike the floors at ground level and above, much of the basement is rectangular, with the building air handling units 9-meters beneath the center of the facility and 2-meter high "crawl spaces" beneath the rooms at the periphery (i.e., including the STEM room) (Figs. 3 \& 4 bottom). Transmission of surface ground vibrations from sources external to the building are likely to be affected by the irregular 9-meter deep mechanical rooms and hallways that extend beneath the entire building, of which the RRC is only a small part. The building columns that support the second floor and roof (i.e., including those above the RRC space) are tied together above the first floor by concrete beams in an irregular radiating pattern that bridges the 9-meter deep rooms and hallways beneath the RRC space. These irregular radiating beam patterns are represented by the solid and dashed blue lines in the floor plan of the STEM suite at the bottom of Fig. 4 and are shown in the photograph in Fig. 5. What effect these rigid bridging structures might have on the horizontal and vertical vibration modes of the building has yet to be investigated. However, we can make a few observations that might suggest a working hypothesis, at least with regard to vibration in the vertical direction.

First, floors within the RRC that have HVAC ductwork suspended beneath them exhibit high levels of vibration. The floor that supports the JEM-2010F STEM is devoid of ductwork (Fig. 5).

Second, the majority of building columns rest on the concrete foundation and basement walls. Thus, the floor of the ground-level "low-vibration" STEM room actually is supported by a rectangular "foundation" at its periphery. Only the "basement walls" of this "foundation" are load bearing for the building. The two exterior foundations are shallow and support only the floor of this one room and the two exterior walls at the level of the first floor.
Third, the suspended concrete slab floor of the low-vibration room also is supported by a single column. This column sits on a caisson 3 - $\mathrm{ft}$ in diameter that flares to a diameter of $9-\mathrm{ft}$ at its base $45-\mathrm{ft}$ below grade. Thus, this column is expected to add stability to the floor. However, it is not the only such column and caisson that supports the floor of the RRC. Although the floor in other rooms tends to vibrate less at locations near the other columns, one does not need to be very far removed from these other columns to measure unacceptable levels of vibration for this application. The floor that supports the JEM-2010F responds differently.

Fourth, note in Fig. 4 (bottom) that the STEM suite is oriented symmetrically around the central building column and that the radiating ceiling beams of the suite bridge the 9-meter deep basement hallway beneath the first floor slab. The actual peripheral "foundation" of this "low-vibration" floor is a square to a first approximation (Fig. 7). The building column is located on a plane of symmetry (indicated by the dashed line). Placed on unsupported sections of this square floor slab are a symmetric array of heavy brick-faced masonry walls that provide two smaller rooms and a decorative indentation of the building exterior within the square periphery. The floor slab under each walled-in area is depressed relative to that under the remainder of the facility. The two areas represented by light purple in Fig. 7 are 8 -in thick slabs offset downward by 5 -in to accommodate decorative stone flooring. Fig. 1 bottom shows a cross-section of this slab offset. The floor slab beneath the heavy brick-faced masonry walls is 13 -in thick. The floor of the decorative indentation in the exterior of the building is depressed 11-in from the level of the laboratory floor and appears to be 12 -in thick. The bottom of this section of floor slab, indicated in gray-green in Figs. 4 and 7, extends 15-in beneath the slab of the laboratory floor (Fig. 5). These aspects of the floor plan are very symmetrical and might be expected to support one or a small number of standing wave patterns. This is the only section of the floor in the RRC that exhibits geometrically complex but symmetrical loading of unsupported floor slab of varying thickness and displacement.

Fifth, there also are a number of asymmetric aspects to the support of this low-vibration floor. These include the basement wall represented in 'red' and the beam and section of thick slab represented in 'dark purple' in Fig. 7 (bottom). The beam and "thick slab" are 24-in thick, except in the light-purple areas in Figs. 4 and 7 where the 5-in depression limits the thickness to 19-in. Finally, the column of the STEM is placed off-axis from the plane of symmetry at a location corresponding to the mirror image of the asymmetric beam. These might be expected to "detune" the floor and to affect damping values of individual resonant modes as is observed experimentally.

Table 2. Velocity Peak PSD measurements

\begin{tabular}{|c|c|c|c|}
\hline LOCATION & $\begin{array}{c}\text { PSD in NS dir. } \\
\mu \mathrm{m} / \mathrm{s} / \mathrm{sqr}(\mathrm{Hz})\end{array}$ & $\begin{array}{c}\text { PSD in EW dir. } \\
\mu \mathrm{m} / \mathrm{s} / \mathrm{sqr}(\mathrm{Hz})\end{array}$ & $\begin{array}{c}\text { PSD in vertical } \\
\text { dir } \mu \mathrm{m} / \mathrm{s} / \mathrm{sqrt}(\mathrm{Hz})\end{array}$ \\
\hline Exterior Pavement 1 & $20.6 @ 3.0 \mathrm{~Hz}$ & $19.3 @ 2.7 \mathrm{~Hz}$ & $24.2 @ 3.0 \mathrm{~Hz}$ \\
\hline Exterior Pavement 2 & $13.2 @ 9 \mathrm{~Hz}$ & $9.6 @ 14.2 \mathrm{~Hz}$ & $17.1 @ 9 \mathrm{~Hz}$ \\
\hline SES Adjacent Room & $4.6 @ 3.1 \mathrm{~Hz}$ & $5.6 @ 3.0 \mathrm{~Hz}$ & $58.1 @ 23.7 \mathrm{~Hz}$ \\
\hline SES crawl space & $3.1 @ 3.1 \mathrm{~Hz}$ & $4.0 @ 3.0 \mathrm{~Hz}$ & $4.1 @ 26.9 \mathrm{~Hz}$ \\
\hline SES Basement on dirt & $2.9 @ 2.9 \mathrm{~Hz}$ & $3.1 @ 3.0 \mathrm{~Hz}$ & $8.0 @ 12.15 \mathrm{~Hz}$ \\
\hline $\begin{array}{c}\text { SES Suspended } \\
\text { Low-Vibration Room }\end{array}$ & $2.5 @ 3.2 \mathrm{~Hz}$ & $2.2 @ 3.7 \mathrm{~Hz}$ & $13.4 @ 28.5 \mathrm{~Hz}$ \\
\hline \hline \multicolumn{4}{|l|}{}
\end{tabular}

Table 3. Displacement Peak PSD Measurements

\begin{tabular}{|l|c|c|c|}
\hline LOCATION & $\begin{array}{c}\text { PSD in NS dir. } \\
\mu \mathrm{m} / \mathrm{sqrt}(\mathrm{Hz})\end{array}$ & $\begin{array}{c}\text { PSD in EW dir. } \\
\mu \mathrm{m} / \mathrm{sqrt}(\mathrm{Hz})\end{array}$ & $\begin{array}{c}\text { PSD in vertical } \\
\text { dir } \mu \mathrm{m} / \mathrm{sqrt}(\mathrm{Hz})\end{array}$ \\
\hline Exterior Pavement 1 & $1.15 @ 2.7 \mathrm{~Hz}$ & $1.0 @ 3.0 \mathrm{~Hz}$ & $1.3 @ 3.0 \mathrm{~Hz}$ \\
\hline Exterior Pavement 2 & $0.24 @ 2.8 \mathrm{~Hz}$ & $0.29 @ 3.4 \mathrm{~Hz}$ & $0.3 @ 9.1 \mathrm{~Hz}$ \\
\hline ERF Basement on dirt 1* & 0.33 & 0.35 & 0.41 \\
\hline ERF Basement on dirt 2* & 0.24 & 0.25 & 0.20 \\
\hline SES crawl space & $0.18 @ 3.1 \mathrm{~Hz}$ & $0.13 @ 3.1 \mathrm{~Hz}$ & $0.08 @ 13.0 \mathrm{~Hz}$ \\
\hline SES Basement on dirt & $0.15 @ 3.1 \mathrm{~Hz}$ & $0.15 @ 2.9 \mathrm{~Hz}$ & $0.11 @ 12.2 \mathrm{~Hz}$ \\
\hline $\begin{array}{l}\text { SES Suspended } \\
\text { Low-Vibration Room }\end{array}$ & $0.11 @ 2.4 \mathrm{~Hz}$ & $0.12 @ 3.0 \mathrm{~Hz}$ & $0.08 @ 4.3 \mathrm{~Hz}$ \\
\hline
\end{tabular}

${ }^{*}$ ERF measurements are from IDE (frequency is unknown)

(1)




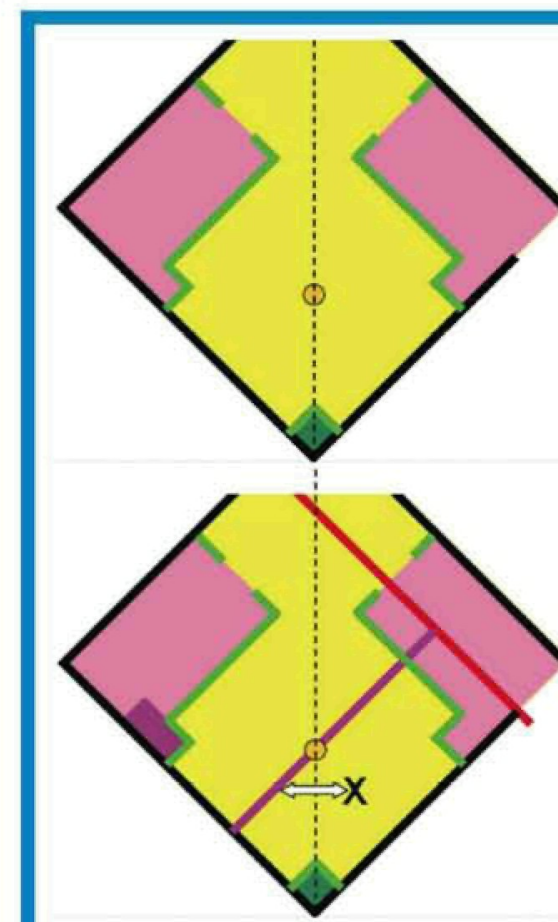

Figure 7. (Top) Symmetrical loading of square floor slab. (Bottom) Asymmetrical structures that might affect the resonant characteristics of the floor in the vertical direction. Black, perimeter supporting foundation and basement walls. Orange circle, building column. Yellow, 8-in thick floor slab. Light purple, 8-in thick slab depressed 5in lower than the adjacent floor slab and covered with stone flooring (See Fig. 1 bottom). Gray-green, exterior 12 -in thick slab with stone flooring depressed 11-in below the laboratory floor. Green, heavy brick-faced masonry walls resting on first floor slab. Red, supporting basement wall. Dark purple, 24-in thick slab (under laboratory) and 19-in thick slab (under depressed slab with stone flooring). $X$ marks the location of the column of the JEOL JEM-2010F TEM/STEM. The double-headed arrow indicates how the location of the STEM is at a mirror image of the asymmetric beam that supports the floor.

limitations on permissible environmental interferences. One of the most ubiquitous of these interferences is building vibration. Construction standards have been developed to limit floor displacement to 0.1 micro-meters, with primary consideration for vibration caused by activities inside the building (such as footfalls from staff walking on the floor and operation of air handling equipment). Current specifications call for floors that are "concrete slab on grade" (often of significant thickness, weighing as much as 34 tons for a floor area of $14 \mathrm{~m}^{2}$ [1]) or rigid "waffle structures" on closely spaced building columns.

According to Medearis [3], structural framing cost is related to weight. To assess the cost per area of useable space in an advanced technology facility, one can divide the weight of a bay area by its area to obtain a value for comparison. By this analysis most current "advanced technology facilities" (microelectronic fabrication) that use either thicker floors or waffle-like constructions have values of 0.2 to $0.5 \mathrm{Kips} / \mathrm{Square}$ foot, with some reaching 0.7 . This is approximately comparable to a reinforced concrete slab of thickness from 16 to 40 inches. In contrast, the RRC STEM room, and many standard building facilities, has a bay weight to bay area ratio more on the order of 0.1 Kips/Square foot and a reinforced slab thickness of 6 to 8 inches.
It is unlikely such construction standards would permit our installation of the JEOL JEM-2010F Scanning Transmission Electron Microscope to meet contract specifications (let alone theoretical limits) due to external vibration in the urban environment that surrounds the UIC campus. The campus is intersected by heavy vehicular street traffic, and its periphery is defined by expressways and both freight and commuter rail lines. The measured vibration performance exceeds waffle or grillage constructions. The floor design of the RRC STEM room comes close to meeting classification NIST-A1 without structural isolation breaks (SIBs) in spite of heavy local traffic conditions and in spite of having air handling units running both in the basement and on the roof of the building. The suspended floor under the STEM appears to exhibit less motion than the ground outside the building. Consequently, the RRC STEM room seems to outperform most modern advanced technology facilities, while at a significantly reduced cost per unit area.

\section{Conclusion}

We have identified a suspended concrete slab floor that outperforms slabon-grade construction in an urban environment in the middle of Chicago. This suspended floor meets NIST-A classification (if active isolation is used for very low frequency motion) and comes close to meeting classification NIST-A1, which was thought to be achievable only with a pneumatically isolated inertia slab. A JEOL JEM-2010F TEM/STEM has been operated near its theoretical resolution limit on this suspended floor without incident for over five years. Further investigation of this unique floor design is expected to provide new, less expensive approaches than are currently available for the design and construction of floors that help compensate for unpredictable external vibration sources in the urban environment. Both analytical characterization laboratories and nanoscience research and fabrication facilities could benefit from this discovery.

\section{Acknowledgements}

We thank the institutional administration of the University of Illinois at Chicago for their support in the planning, design, and construction of this research and teaching facility. M. Bulent Ozer, Curt Preissner and Todd Spohnholtz performed and analyzed vibration measurements. $M+W$ Zander U.S. Operations, Inc. assisted in preparing floor plans for the figures.

\section{References}

1. "Laboratory Design for High-Performance Electron Microscopy," MA O'Keefe, JH Turner, JA Musante, CID Hetherington, AG Cullis, B Carragher, R Jenkins, J Milgrim, RA Milligan, CS Potter, LF Allard, DA Blom, L Degenhardt and WH Sides, Microscopy Today (May 2004), 8-14.

2. "Design of stiff, low-vibration floor structures," H Amick, S Hardash, P Billett and RJ Reaveley, Proceedings of SPIE, Vol. 1619, San Jose, CA, November 4-6, (1991) pp. 180-191.

3. "Rational vibration and structural dynamics evaluations for advanced technology facilities," K Medearis, Journal of the Institute of Environmental Sciences, Sep/Oct (1995) 35-44.

4. "Facility vibration issues for nanotechnology research," H Amick, M Gendrequ and CG Gordon, Symposium on Nano Device Technology, National Chiao-Tung University, Hsinchu, Tawain, May 2-3 (2002).

5. "Practical aspects of atomic resolution imaging and analysis in STEM," EM James and ND Browning. Ultramicroscopy, 78 (1999) 125-139.

6. "Vibration control design of high technology facilities," E Ungar, DH Sturz and H Amick. Sound and Vibration, 24 (7) (1990) $20-27$.

7. "On generic vibration criteria for advanced technology facilities," H Amick. Journal of the Institute of Environmental Sciences, 40 (5) (1997) 35-44.

8. "Dynamic characteristics of structures extracted from in-situ testing," H Amick, M Gendreau and A Bayat, Proceedings of the SPIE Conference on Opto-mechanical Engineering and Vibration Control, Denver, CO, July 20 (1999)

9. "An active microvibration isolation system for hi-tech manufacturing facilities," $\mathrm{H}$ Yoshioka, Y Takahashi, K Katayama, T Imazawa and N Murai. ASME Journal of Vibration and Acoustics 123 (2001) $269-275$.

10. International Organization for Standardization (ISO). Technical Specification: Mechanical vibration and shock - Vibration and shock in buildings with sensitive equipment - Part 1: Measurement and evaluation. ISO/TS 10811-1 (2000).

11. International Organization for Standardization (ISO). Technical Specification: Mechanical vibration and shock - Vibration and shock in buildings with sensitive equipment - Part 2: Classification. ISO/TS 10811-2 (2000).

12. Integrated Dynamics Engineering (IDE) Site Survey Report, A Lai (1996)

13. "Vibration Characteristics of an APS Lab Facility in Building 401. Argonne National Laboratory, Light Source Notes," TJ Royston, http://www.aps.anl.gov/techpub/lsnotes/ 1s263/ls263.html (1998). 


\section{PELCO BioWave ${ }^{\circledR}$ Laboratory Tissue Processing System}

First in:

- Tissue processing technology for EM

- Controlling microwave oven energy and heat

- Controlling the microwave environment: PELCO Coldspot ${ }^{\circledast}$ (patented)

- Controlling true wattage for better MW processing

- Flow-through load cooling

- Complete protocols for fixation, dehydration, infiltration and curing with MW controlled vacuum assisted MW processing

- and now another First:

Automatic flow-through MW fixation and decalcification with dehydration and infiltration (Model DFR-10)

Today's lab needs equipment that can keep pace with the ever-quickening need for rapid specimen turnaround while maintaining quality as high as ever. The PELCO BioWave ${ }^{\otimes}$ is the tissue processor of choice for your needs: Fixation, dehydration, resin infiltration, staining, decalcification, immunocytochemistry, in vivo vital staining, in situ hybridization and extraction of DNA.

Look through the more than two dozen papers cited on our web site (http://www.tedpella.com/34700_html/ref.htm) where the authors successfully used PELCO ${ }^{\otimes}$ microwave technology to process their samples. There is no more need to wonder whether this technology will work. This laboratory processor will produce quality, repeatable results, allowing you to standardize these procedures over a wide variety of protocols.

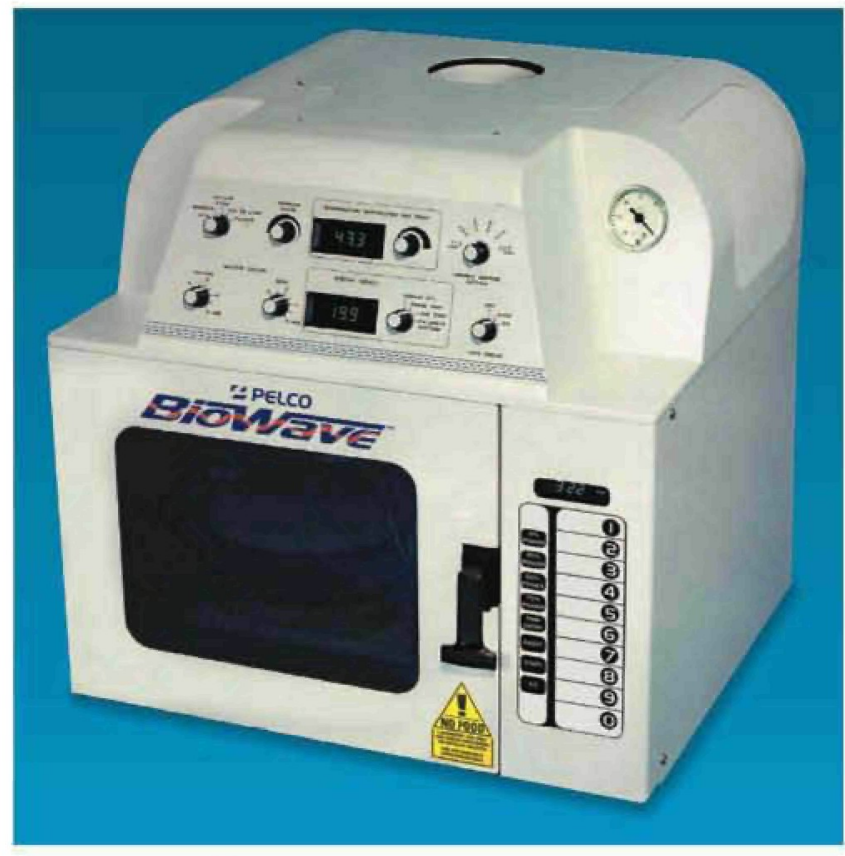

PELCO BioWave ${ }^{k}$ Laboratory Tissue Processing System For more details: http:/Www:tedpella.com/34700_html/34700.htm

\section{2

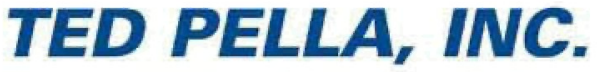 \\ Microscopy Products for Science and Industry}

4595 Mountain Lakes Blvd., Redding, CA 96003-1448

Phone: 530-243-2200 or 800-237-3526 (USA) FAX: 530-243-3761

Email: sales@tedpella.com Web Site: http://www.tedpella.com

PELCO, PELCO BioWave and PELCO ColdSpot are registered trademarks of Ted Pella, Inc. All rights reserved. CTed Pella, Inc., 03-04.

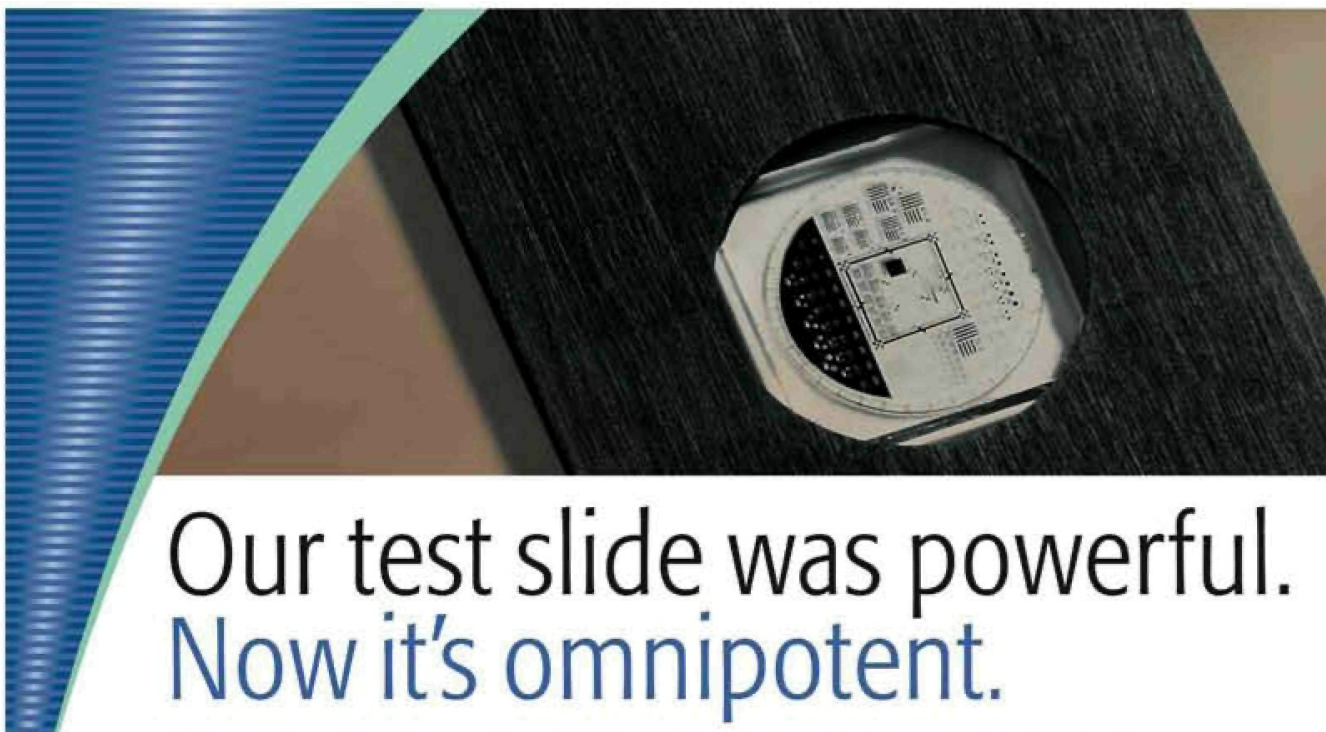

Introducing the Generation III Test Slide from Richardson Technologies.

Is your microscope delivering the exacting performance you demand? Are you compromising your results because of undetected deficiencies in your instrument?

Richardson's new Generation III Slide provides the insights to take magnification, image resolution and shape identification to unheard of levels of precision - in even the highest magnification microscope and imaging systems. Both the low ( $1 \mathrm{x}$ to 20x objectives) and combined low/high ( $1 \mathrm{x}$ and up) versions offer more than 20 different test patterns, down to a revolutionary 50 nanometres - helping you calibrate your instrument with unprecedented accuracy.

\section{Doubtful?}

View Life without Limitations $\rightarrow$ www.richardson-tech.com $\rightarrow 1.905 .951 .7058$

or 1.888.494.4541 (Canada \& USA only)

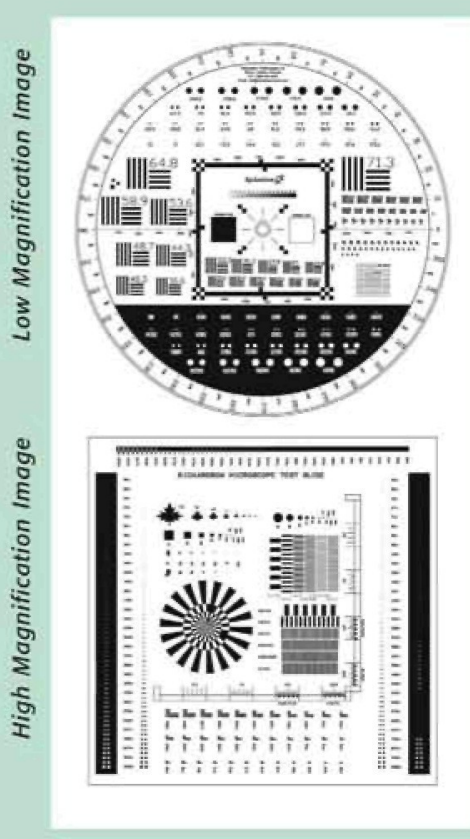

Richardson 